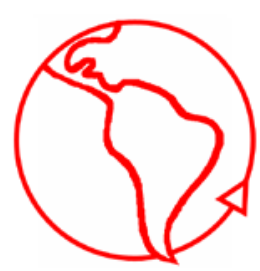

\title{
La sociedad moderna: una sociedad capitalista funcionalmente diferenciada
}

\author{
Modernity as a Functionally Differentiated Capitalist Society
}

Uwe Schimank

Instituto de Sociología, Universidad de Bremen, Alemania

\begin{abstract}
Resumen
El presente artículo presenta la idea teórica relativa a que la sociedad moderna puede ser concebida como una sociedad capitalista sin contradecir su caracterización como sociedad funcionalmente diferenciada. Propondremos para ello un modelo analítico de una sociedad capitalista basado en tres componentes. El primero de ellos refiere a estructuras y dinámicas intersistémicas mediadas por el dinero, las cuales son específicas de las relaciones entre la economía moderna y otros subsistemas sociales. El segundo componente identifica a los mercados como estructuras de gobernanza intrasistémicas que poseen dinámicas peculiares, las cuales no pueden ser encontradas en otros subsistemas de la sociedad moderna. Ambos componentes están íntimamente ligados: sólo debido a que los sucesos intrasistémicos de la economía irradian profundas repercusiones intersistémicas hacia los otros subsistemas sociales, es posible hablar de una sociedad capitalista producida por una economía capitalista. Estos dos componentes se encuentran acompañados por un tercero: dado que vivimos en una sociedad capitalista, ésta moldea nuestras acciones como un patrón cultural general de orientación y se convierte, de esta manera, en una profecía autocumplida.
\end{abstract}

Palabras Clave: Diferenciación Funcional; Capitalismo; Sociedad Moderna; Economía; Teoría de Sistemas Sociales

\begin{abstract}
This contribution presents the theoretical idea that modern society can be conceived of as a capitalist society without contradiction to its characterization as functionally differentiated. A three- component analytical model of capitalist society is proposed. The first component refers to inter-systemic structures and dynamics mediated by money which are peculiar to the relations of the modern economy to the other societal sub-systems. The second component identifies markets as intra-systemic governance structures of the economy with peculiar dynamics that cannot be found in other sub-systems of modern society. Both components are interrelated: Only because the intra-systemic structures and dynamics of the economy have profound inter-systemic repercussions in all other sub-systems, one can speak of a capitalist society brought about by a capitalist economy. These two components are accompanied by a third one: that we live in a capitalist society shapes, as a general cultural pattern of orientation, our actions and thereby becomes a self-fulfilling prophecy.
\end{abstract}

Keywords: Functional Differentiation; Capitalism; Modern society; Economy; Social Systems Theory

Revista Mad - Universidad de Chile

Revista del Magíster en Análisis Sistémico Aplicado a la Sociedad

Facultad de Ciencias Sociales, Departamento de Antropología.

Universidad de Chile

www.revistamad.uchile.cl 


\section{Introducción"}

Si se pregunta a la gente común en la calle si vivimos en una sociedad donde la economía posee una posición dominante en toda la sociedad, la respuesta habría de ser clara: la gran mayoría estaría de acuerdo. Respecto de la sociedad alemana por ejemplo, el semanario "Die Zeit" constata en su edición del 22 de septiembre del 2005 un "convencimiento común entre votantes, medios de comunicación y políticos respecto a que para el futuro bienestar de la nación el factor económico resulta decisivo, si es que no es el único". Dicho convencimiento se ve reforzado con seguridad con la reciente y dramática evolución de los mercados financieros globales, la que ha llevado a la "economía real" a una profunda recesión. El "purgatorio del mercado" (Jessen 2005) no deja en paz a nada ni a nadie.

Una mirada a los diagnósticos sociológicos contemporáneos desde los años 80s - e incluso anteriores- muestra una imagen muy similar (Schimank 2002). En dichos diagnósticos se asume, casi incuestionablemente, que las dinámicas y estructuras de toda la sociedad moderna están profundamente adaptadas a los intereses de la economía y son modeladas por dichas operaciones. Más aún, se vuelven a subrayar con mayor vigor, en comparación con los años 60s, los siempre presentes lados oscuros de la dominación económica en los eventos de la sociedad -explicando que ya sea mediante la globalización o el "neoliberalismo", el "capitalismo flexible" (Sennett 1998) o la "sociedad del trabajo", es que se acaba el trabajo (Offe 1984).

También algunas perspectivas teóricamente más fundadas sobre la sociedad moderna reconocen a la economía, como área parcial, un primado social general ${ }^{1}$. Todas las variedades del marxismo hacen esto explícitamente, y evidentemente se asume esto también de manera implícita y con un signo totalmente diferente en las ciencias económicas. Mientras que la segunda perspectiva observa las bendiciones más relevantes de la modernidad ancladas en la "economía de libre mercado", la primera le asigna a los "capitalistas" la responsabilidad principal de los mayores males sociales.

No es necesario recapitular aquí las múltiples denominaciones que se han dado a la forma de la economía moderna. Me referiré en lo sucesivo a la economía capitalista - al igual que Max Weber- de manera valorativamente neutral, es decir sin una emoción crítica predeterminada. Los elementos constitutivos de este tipo de economía son bien conocidos y ampliamente aceptados (Kraemer 2001: 113 y s.; Willke 2006: 7 y ss.; Berger 2008): en primer lugar, la emancipación hacia una orientación al valor de cambio frente a la producción de valores de uso, apoyada en un afán de ganancia como valor rector de la actividad económica; en segundo lugar, la persecución de un afán de ganancias en mercados donde oferentes de mercancías compiten mutuamente; y en tercer lugar la transferencia de todos los factores de producción -naturaleza, capital y trabajo- en mercancías que son comerciadas asimismo en mercados de acuerdo con esta lógica del valor de cambio. Visto desde la perspectiva de una teoría de la diferenciación de la sociedad, estas son precisamente las características que apoyan estructuralmente la diferenciación social del sistema económico ${ }^{2}$. En este sentido concuerda la perspectiva teórica de la diferenciación de la economía moderna con su identificación como capitalista: una economía funcionalmente diferenciada es una economía capitalista.

\footnotetext{
* [N. del T.] Traducción de Hugo Cadenas con autorización expresa del autor. Título original: Die Moderne: eine funktional differenzierte kapitalistische Gesellschaft. Berliner Journal für Soziologie, Jg. 19, Heft 3, 2009, S. $327-351$. Quisiera agradecer a Uwe Schimank por autorizar y corregir esta versión. Los posibles errores o imprecisiones en la traducción son de responsabilidad del traductor.

${ }^{1}$ Para una visión general y concisa de estas discusiones económicas ver Willke (2006a)

${ }^{2}$ Como accesos teóricos diferentes desde la teoría de la diferenciación, véase Parsons y Smelser (1956), Luhmann (1988) así como la muy minuciosa comparación entre Karl Marx y Niklas Luhmann realizada por Pahl (2008).
} 
¿Es acaso por esto una sociedad funcionalmente diferenciada una sociedad capitalista? Esto significaría que vivimos en una sociedad que estaría marcada amplia y profundamente por su economía capitalista, es decir más que por los sucesos de otros sistemas parciales, como por ejemplo la política democrática o el progreso del conocimiento científico: "El capitalismo (...) es a la vez un orden económico y un orden social" (Willke 2006: 8). Tanto la variante teórica de la diferenciación de Talcott Parsons como de Niklas Luhmann niegan con vehemencia semejante primado social total de la economía para la sociedad moderna ${ }^{3}$. Para Parsons (1975b: 174 y s.) tal punto de vista correspondería a una "teoría de un factor" perteneciente a un pensamiento sociológico de un "nivel de Kindergarten" y Luhmann (1973: 81; 1979: 218) de manera similar se refiere despectivamente a esta perspectiva como reliquias "veteroeuropeas" de la autocomprensión de la sociedad moderna ${ }^{4}$.

En síntesis: el hecho que vivimos en una sociedad capitalista parece ser tan evidente que para algunos no hace falta hablar más de ello, mientras que otros consideran esta idea es tan obsoleta que tampoco creen que hace falta hablar más de ella. La interacción entre estas dos posiciones es desde hace décadas la de una casi completa evitación en torno a la pregunta de si vivimos en una sociedad capitalista. Dicha pregunta es ante todo teórica, sólo después -y sobre dicha base- puede ser explicada empíricamente. De los tres pasos que enumeraremos a continuación, sólo el primero de ellos puede ser desarrollado acá: (1) construcción de un modelo teórico coherente; (2) derivación de criterios de prueba operativos acerca de si el modelo refleja la realidad empírica; y (3) verificación o falsación empírica de dichos criterios. Me referiré a este primer paso sobre la base de una perspectiva teórica de la diferenciación, a pesar de que sus máximos representantes, como he mostrado anteriormente, sostengan precisamente que no habría un primado de la economía o de algún otro subsistema por sobre toda la sociedad. Quiero mostrar frente a dicho argumento que la sociedad moderna puede ser pensada como una sociedad capitalista sin contradecir su caracterización como una sociedad funcionalmente diferenciada, más aún: sólo y únicamente como sociedad funcionalmente diferenciada se puede entender adecuadamente a la sociedad capitalista, así como por su parte la diferenciación funcional se yergue necesariamente en base al capitalismo.

A continuación presentaré un modelo teórico del capitalismo en base a tres componentes. El primer componente se refiere a estructuras y dinámicas intersistémicas que distinguen al sistema económico en sus relaciones con todos los demás subsistemas de la sociedad moderna. Complementariamente, el segundo componente designa estructuras y dinámicas intrasistémicas del sistema económico que no pueden ser ubicadas en otro subsistema. Ambos componentes están íntimamente ligados. Sólo debido a que los sucesos intrasistémicos de la economía irradian profundas repercusiones intersistémicas hacia los otros subsistemas sociales, es posible hablar de una sociedad capitalista producida por una economía capitalista. A estos dos componentes de un nivel estructural de los eventos sociales se añade un tercer componente cultural: el capitalismo es también un patrón de orientación [Deutungsmuster] de los sucesos sociales el cual impregna la acción.

\section{La centralidad intersistémica de la economía}

A continuación tomaré en consideración la posición de la economía en el entramado intersistémico de los subsistemas de la sociedad moderna. Desde la teoría de la diferenciación resulta claro que entre todos los subsistemas existen diversas interdependencias entre sus servicios -visto desde la teoría del actor, corresponden estos

\footnotetext{
${ }^{3}$ Sobre la contribución sociológico-económica de ambos, véase Beckert (1997: 199 y ss.)

${ }^{4}$ Véase en Schimank (2005a) acerca de algunas reflexiones e ideas dispersas con las cuales tanto Parsons como Luhmann se desprenden una y otra vez de dicha doctrina anti-marxista auto-formulada.
} 
subsistemas a organizaciones proveedoras de servicios subsistémicos [Leistungsorganisationen] y a portadores de roles de desempeño [Leistungsrollenträger]*. Dicho entramado de interdependencias proporciona servicios económicos esenciales para todos los demás subsistemas sociales. De este hecho no se deriva por supuesto un primado social general de la economía. Esto pues los demás subsistemas -piénsese solamente en la política, el derecho, la ciencia o la educación- son igualmente irremplazables en sus servicios. No por último, la economía es también existencialmente dependiente de de ellos, como así también ellos dependen de la economía. El primado social general de la economía no se constituye, de este modo, a partir de la condición especial y sustancial relativa a su contribución a la reproducción social en general, sino según la tesis que se desarrolla aquí- de manera relacional, es decir: desde la posición prominente que posee la economía en el entramado total de interdependencias de todos los servicios sistémicos. Bob Jessop (2002: 25) se refiere con claridad a una "dominancia ecológica" en el sentido de una "capacidad estructural de un sistema, en una ecología de auto- organización de sistemas, para imprimir su lógica de desarrollo en las operaciones de otros sistemas, de manera mucha más marcada que la capacidad que tienen estos sistemas para imponer sus respectivas lógicas al primero". En la siguiente sección debe ser examinado con más detalle si acaso se trata realmente de una "lógica de desarrollo" de la dinámica económica.

El medio que caracteriza esta influencia que producen los eventos de la economía en todos los demás subsistemas es el dinero. La economía, y solamente ella, provee a los actores de la sociedad moderna con dinero. Las empresas se proveen de dinero directamente en la economía, aunque también obtienen algo de éste gracias a subsidios estatales. Los miembros individuales de la sociedad obtienen el dinero que necesitan a través de actividades laborales, en presupuestos privados, y lo reciben en parte - algunos también completamente- como transferencia de ingresos del Estado. El Estado moderno es un "Estado de Impuestos" (Hickel 1976), es decir, financia sus gastos a través de la recaudación de impuestos, los cuales obtiene a partir de empresas, de miembros individuales de la sociedad y de las restantes organizaciones proveedoras de servicios de los demás subsistemas. Una gran parte de dichas organizaciones, como hospitales, cortes, escuelas o universidades, son financiadas en gran medida por el Estado, pues la mayoría de las veces se financian sólo en una pequeña parte a través de cobros o tasas que cubren sus gastos, o también a través de donaciones de patrocinadores o clientes individuales u organizacionales. Las organizaciones de los demás subsistemas sociales, al igual que los miembros individuales de la sociedad, son en parte directa e indirectamente -y acá especialmente por intermedio del Estado- dependientes monetariamente de la economía (Schimank 2009).

El dinero, como un recurso para las producción de servicios en la economía, así como también en todos los demás subsistemas no es como lo representan tanto Parsons (1967a, 1967b, 1975a, 1968) como Luhmann (1976, 1997: 316 y ss.), es decir, simplemente como un medio de comunicación simbólicamente generalizado junto a otros como el poder, el amor o la verdad ${ }^{5}$. El dinero es más bien - como antes Georg Simmel (1989) lo destacó en numerosas y certeras observaciones- aquel medio que influye en los

\footnotetext{
* [N. del T.] Se ha traducido Leistungsorganisation siguiendo la recomendación del autor (comunicación personal) relativa a que estas serían "sub-systemic service providers". El concepto de Leistungsrollenträger se refiere al concepto de "desempeño" en el sentido que Luhmann y Stichweh dan al concepto de "rol de desempeño" versus "rol de público". El autor usa en lo sucesivo estos dos ejemplos de "actores" sociales: organizaciones proveedoras de servicios subsistémicos y portadores de roles de desempeño.

${ }^{5}$ Jürgen Habermas (1980) ha señalado tempranamente las especificidades del medio dinero. Christoph Deutschmann $(1999,2000,2007 a, 2008)$ ha puesto en relieve recientemente de manera decidida lo incomparable del dinero y otros medios de comunicación. Una iniciativa similar se encuentra en Paul (2004) y Kuchler (2005). Incluso Parsons y Luhmann han reconocido siempre que el dinero sería el más avanzado "técnicamente" de los medios de comunicación, sin que sin embargo a partir de esta observación se puedan extraer conclusiones adicionales.
} 
demás y que es social y factualmente más infinita y universalmente utilizable que los demás medios. Así, el poder legítimo está atado territorios, al contenido de determinadas atribuciones -es decir, a un espectro limitado de posibles fines para el uso del poder- y a posiciones autorizadas. La verdad solamente puede ser manejada por expertos y cada verdad es determinada en su contenido, por tanto sólo puede ser usada de manera específica y en contextos pertinentes. Por ejemplo, sólo un meteorólogo puede argumentar convincentemente con un modelo de clima y resulta más bien improbable que éste sirva como medio para influir en las oportunidades educativas de los niños de clase baja o para intervenir en un conflicto marital. En el amor, por su parte, sus posibilidades de aplicación son con certeza factualmente más variadas, pero socialmente se reducen en extremo. Quien es amado puede pedir a su amante casi todo, pero sólo a él. El dinero, en cambio, es utilizable de manera espacialmente global, es posible comprar prácticamente cualquier cosa y sobre todo sin determinar temporalmente en el presente qué será comprado mañana, puede ser manejado por cualquiera frente a cualquiera y puede ser cuantificado con mayor precisión. Este grado incomparable de generalización multidimensional del dinero significa que su presencia o ausencia se puede sentir en todas partes en la sociedad, incluso entre todos los demás subsistemas además de la economía, y no sólo por algunos actores y sólo en ciertas ocasiones, sino en todas partes. Políticos y museos, hospitales e institutos de investigación, familias y periodistas, todos ellos sienten constantemente el pulso de la economía y lo notan en su propia -amplia o reducida- solvencia.

Saber cuánto o cuán poco dinero se posee y se poseerá a largo plazo - este efecto que tienen los eventos económicos en toda la sociedad- tiene un significado completamente diferente para cada actor de cada subsistema, del mismo modo como sin duda los acontecimientos en los demás subsistemas tienen efectos importantes en toda la sociedad. Así el sistema del derecho se ocupa en todas partes de la seguridad jurídica, la ciencia proporciona sus conocimientos en todas partes, el sistema educativo transmite competencias a lo ancho de la sociedad de acuerdo a sus necesidades respectivas, el periodismo informa a todos los subsistemas y sobre todos los subsistemas, y la política opera de manera regulativa y conductora en todos los subsistemas. No es el alcance de los efectos de la economía en los otros subsistemas lo decisivo. Más bien uno puede argumentar con - y al mismo tiempo contra- Parsons en base a su "jerarquía cibernética de control" de modo de determinar la especificidad de esta acción transversal a toda la sociedad que es característica del dinero. El dinero es en la "jerarquía cibernética de control" el medio de comunicación económico más importante para la sociedad, debido a su aplicación "energética" universal y las conexiones de acciones y servicios que su fuerza posibilita (Parsons 1976: 171 y ss.; Schimank 1996: 112 y ss.). Se puede decir con Simmel (1989: 305) que el dinero es "el medio absoluto". Parsons (1975b: 174s) mismo asume luego sin embargo "la importancia preponderante de los más elevados elementos cibernéticos para la estructuración de los sistemas de acción", es decir ve una prioridad de los factores "reguladores" por sobre los "energéticos". Frente a esto se debe indicar que las influencias "reguladoras" por parte del derecho, la ciencia, la educación, el periodismo o la política, sobre la acción en los otros subsistemas tienen naturalmente siempre sólo una importancia factual fija limitada. Una norma legal o un artículo de prensa tematizan siempre un espectro que describe reducidamente lo que ocurre por ejemplo en la ciencia todo lo demás es irrelevante desde el principio. El dinero, por el contrario, es en principio universalmente relevante para toda acción que ocurra en un subsistema determinado. Esto pues el dinero, como "energía" disponible, actúa en todas partes permitiendo intenciones no fijadas con anterioridad -o cuando él hace falta, se tornan imposibles todas las cosas posibles. Y porque con dinero se puede hacer todo lo posible, pero no todo al mismo tiempo, se debe ponderar y decidir. De este modo, bajo la forma de un cálculo frente a la escasez es que se representa a los actores el acceso "energético" total a todos los eventos de los demás subsistemas a partir del dinero -mejor aún, a partir de la economía. Este acceso puede intensificar la presión de economización para un determinado actor - un médico, un museo o una madre- y se hace sentir como tal en forma de omisiones 
indirectas, de manera distinta al acceso a otros subsistemas como el derecho o el periodismo. Es decir, como en realidad carezco de los pagos en dinero necesarios, debo ver por mí mismo como me las arreglo con eso.

La presión de economización se mueve en una escala de cinco niveles (Schimank \& Volkmann 2008). En el nivel 1 no existe conciencia entre organizaciones proveedoras de servicios subsistémicos y roles de desempeño respecto de los costos. El dinero para cubrir costos no representa un problema para estos actores que deciden sobre el diseño de los servicios, ya sea porque estos costos están generosamente asignados, o porque se procuran en un segundo plano sin que tengan que preocuparse por ello. En el nivel 2 la conciencia de costos es formulada como una "expectativa de lo que debiera ser" [SollErwartung] (Dahrendorf 1958: 37 y ss.). Los costos debieran ser tomados en cuenta y, cuando sea posible, se debe ahorrar. El nivel 3 se caracteriza por una conciencia de costos, la cual se representa en una "expectativa del deber ser" [Muss-Erwartung]: la producción no debe generar pérdidas. El nivel 4 se alcanza cuando la obtención de ganancias está puesta como una "expectativa de lo que debiera ser" [Soll-Erwartung]: además de evitar las pérdidas, algunas ganancias discretas son deseadas. Finalmente, en el nivel 5 la obtención de ganancias es una "expectativa del deber ser" [Muss-Erwartung]: con la producción se debe obtener en primer lugar el mayor dinero posible.

Mientras que las empresas, como organizaciones del sistema económico, deben alcanzar el nivel 4, o al menos siempre el nivel $3^{6}$, los portadores de roles de desempeño y las organizaciones proveedoras de servicios subsistémicos pueden operar permanentemente en el nivel 1 -a condición de que las finanzas estatales fluyan con abundancia o también, secundaria o alternativamente, ocurra algo similar con los aportes de sus miembros, los cobros o tasas y las donaciones de hogares privados o los honorarios por encargos de empresas. Hubo tales tiempos y pueden asimismo regresar, sin embargo existen también fases en las cuales -como en la actualidad- museos, universidades, hospitales u oficinas gubernamentales deben alcanzar al menos el nivel 3 y de este modo las hasta ahora generosas asignaciones de recursos y tácitas garantías subsidiarias del Estado o de inversionistas privados deben ser reembolsadas.

Los inversionistas estatales, por su parte, los cuales financian servicios de subsistemas, entran en una tal presión de economización cuanto más fuerte es el involucramiento del Estado de Impuestos en una crisis financiera (Schimank 2010). A partir de la "financiación a costa de los gastos de estado" (Grauhan \& Lindner 1974: 63) por medio de la economía, se deriva una "acumulación como referente" (Offe \& Ronge 1976: 55 y ss.) para la acción estatal (Offe 1975: 24 y s.; Grauhan 1975: 54 y ss.; Grauhan \& Hickel 1978). Debido a que el monto de los ingresos fiscales depende directamente de la prosperidad de la economía ${ }^{7}$ y dicha situación no se puede lograr ni mantener a través de cualquier recurso estatal como una mera política económica - cuya influencia en el mejor de los casos es más bien débil- muchas decisiones estatales se ven enfrentadas a la prioridad estructural de las perspectivas económicas por sobre todos los demás intereses sociales. Formulado de manera positiva, el estado debe producir y salvaguardar un "saludable clima de inversión" para evitar que las empresas ejerzan su "derecho de propiedad negativo", es decir se acojan a su derecho a no invertir (Offe 1975: 204). Esta consideración de la política sobre

\footnotetext{
${ }^{6}$ Sólo se puede hablar en la economía de una creciente presión de economización cuando la etapa 5 se convierte en directriz -como por ejemplo en el "capitalismo financiero", con la insistencia en la maximización del beneficio a corto plazo por parte de los fondos de inversión (Windolf 2005).

${ }^{7}$ La alternativa viable para aumentar los impuestos es posible de todos modos a corto plazo y dentro de límites muy estrechos de modo de no disminuir la tendencia a invertir y que por lo tanto decline la masa de aquello que puede ser gravado.

${ }^{8}$ Evidentemente el Estado no es ningún actor monolítico que tiene en mente siempre y al unísono los intereses de prosperidad económica. Sin embargo el desprecio por dichos intereses se paga similarmente como aumentos de impuestos.
} 
las necesidades de la economía se hace más fuerte cuando las finanzas estatales se hacen más ajustadas, que es lo que sucede en una crisis económica de largo aliento tal como la que prevalece desde la década de los 80 s en muchos países occidentales. Entonces domina la "mano derecha" del Estado (Bourdieu 1998), es decir: los recursos financieros y económicos se destinan a mejorar el clima de inversión, mediante el ahorro en los gastos del Estado de bienestar y mediante estímulos y apoyos simultáneos a la inversión económica y al abaratamiento de la fuerza de trabajo. La consecuencia de esto es que los beneficios monetarios sociales y del Estado de bienestar son los que más sufren.

El mismo efecto se difunde hacia los presupuestos privados, cuyos ingresos disponibles se elevan y caen - al igual que los ingresos fiscales- con la prosperidad económica. En el caso extremo del desempleo se reducen especialmente los fondos para el consumo y junto con ello el dinero que fluye de diversas maneras hacia el sistema educativo, religioso o del arte. Finalmente, se hace difícil para las organizaciones proveedoras de servicios de todos estos subsistemas conseguir dinero en base a encargos pagados por empresas o a través de patrocinadores.

De este modo, el mecanismo de apoyo de la economía en la estructura básica de la sociedad funcionalmente diferenciada corresponde a datos económicos - directa o indirectamente- anónimos generados por efecto de agregación a partir de la acción recíproca de numerosos actores económicos, es decir, ejercido por ningún actor establecido en particular, aunque su presión de costos para la producción de servicios de los demás subsistemas puede ser a veces fuerte o a veces débil. En ocasiones este mecanismo de apoyo se afloja tanto que casi no se siente o incluso se olvida -como por ejemplo en la Alemania de la década de los 60 s cuando el "breve sueño de la eterna prosperidad" (Lutz 1984) era la sensación generalizada. Pero tan pronto como surge la situación económica en los demás subsistemas, este mecanismo se puede apretar de manera más o menos drástica - y entonces todos recuerdan con pesar que vivimos en una sociedad en la cual los intereses económicos marcan la pauta.

Esta presión de costos antes mencionada corresponde a uno de los tres rasgos propios de la presión de economización en toda la sociedad. El segundo rasgo es la presión de mercantilización, la cual se manifiesta en el hecho que empresas y empresarios apuntan constantemente como objeto para sus inversiones a aquellas partes y formas de producción de servicios de otros subsistemas, las cuales prometen ser capaces de operar de forma rentable o más rentable. Cuando en las etapas de estagnación de la economía finalmente escasean oportunidades lucrativas de inversión para la producción de bienes y servicios, la mirada de los inversionistas se dirige sin reservas o reparos hacia los demás subsistemas, desde la religión al sistema legal o hasta a las relaciones íntimas. Las formas de mayor alcance de mercantilización se representan bajo la forma de privatizaciones de servicios estatales o afines al Estado, de servicios de otros subsistemas o incluso del propio sistema político, como ha sucedido en las últimas décadas en muchos países (Engartner 2007). En otras ocasiones surgen ofertas privadas de manera simultánea y en competencia con la oferta existente, como por ejemplo gimnasios o universidades mercantiles, o emisoras de radio y televisión privadas. La mercantilización se presenta incluso más allá desde la producción de servicios de otros subsistemas donde se ha expandido ya hace tiempo, como por ejemplo en la ropa deportiva y el equipamiento adecuado, los cuales se convierten en cada vez más importantes y costosos para el ejercicio físico, o en las relaciones íntimas donde las salidas a comer en restaurantes y la comida preparada reemplazan cada vez más a la propia cocina9. Por último, la mercantilización también puede expresarse como desinhibición de la orientación hacia la ganancia económica en otros subsistemas -como lo que sucede cuando algunos

\footnotetext{
${ }^{9}$ Muy instructivo sobre este particular resulta el estudio de Eva Illouz (2003) sobre la dependencia del consumo por parte del amor romántico.
} 
deportistas profesionales, artistas, abogados, médicos o periodistas se alejan de los escrúpulos de sus principios ético- profesionales.

En tercer lugar, la producción de servicios de los subsistemas es llevada a cabo a partir de señales de advertencia y de aviso de tipo financiero, por ficciones de racionalidad ${ }^{10}$ económica, en línea con exigencias económicas de prosperidad -por ejemplo cuando algunos advierten que la investigación científica debe centrarse más bien en las necesidades de innovación tecnológica requeridas por las industrias, o cuando las iglesias reciben el mensaje de que, en vista de favorecer a sectores económicos de alto crecimiento en el futuro, resulta inoportuno articular excesivos escrúpulos teológicos contra la investigación con células madre. La presión de economización puede extenderse asimismo más allá de la orientación a la ganancia y la evitación de pérdidas, puede hacerlo buscando una adaptación interna de la producción de servicios de los subsistemas en torno a la interpretación hegemónica de aquello que la economía considera necesario ${ }^{11}$. La amplitud de esta presión de racionalidad que instruye y legitima a la presión de costos y a la presión de economización es enorme. El hasta hace poco permanente triunfo del pensamiento "neo-liberal" por sobre la forma de todos los subsistemas sociales, constituye un ejemplo gráfico de cómo la sociedad en su conjunto puede ser considerada y tratada como si en cualquier situación sólo se demandara una acción "empresarial".

Una presión de economización en dirección al nivel 3 conduce a un peligro para la autonomía de la producción de servicios de los subsistemas. Entonces "un poco de dinero" (Luhmann 1983: 39) puede llevar a que no se realice una instrucción médica, un requerimiento científico o un deseo artístico, los que ya no orientan su producción de servicios hacia la guía superior que dan sus propios códigos, sino que se subordinan de manera explícita bajo una perspectivas de costos. Este peligro potencial aparece con claridad si parte importante y creciente de la producción de servicios de los subsistemas es asumida por empresas u organizaciones, las cuales deben comportarse de manera "empresarial". Este peligro no consiste, dicho con claridad, en que esta posibilidad se realice de manera inevitable -pero mientras más crece, más probable se hace y más drásticas son entonces sus consecuencias. En este lugar es importante recordar que la autonomía de los subsistemas no se reduce o elimina por completo cuando la lógica autorreferencialmente cerrada de la acción específica del subsistema es por largo tiempo y en una gran extensión suprimida y sustituida por la lógica de la acción económica ${ }^{12}$. Por cierto, pueden surgir extensas pérdidas de autonomía, de tal manera que los efectos de los eventos económicos pueden reducir de manera más o menos drástica el espacio de movimiento de las operaciones autorreferenciales marcadas por códigos de los otros subsistemas. No sólo el acceso directo al código puede reducir la autonomía de los subsistemas, sino también la formulación indirecta para sí por parte de la economía de estos códigos que ha dejado a su vez intactos. Los actores de un sistema parcial bien pueden tener total libertad para orientar su acción hacia su código autorreferencial y hacia nada más, pero si la situación financiera y sus excesivos programas de enmarcación determinan de manera estrecha el posible "goce" del código respectivo, se producen efectos muy fuertes como una marcada restricción de la autonomía o una derogación directa del código.

Nuestra construcción teórica se ha movido hasta ahora dentro del punto de vista analítico de la integración sistémica. La integración sistémica de la sociedad funcionalmente diferenciada, entendida como coordinación entre sus subsistemas, está prefigurada económicamente. Esta idea tiene que ser completada ahora bajo el punto de vista de la

\footnotetext{
${ }^{10}$ En términos generales acerca de las ficciones racionales véase Schimank (2005b: 373 y ss.).

${ }^{11}$ Véase aquí también en Schimank (2008: 221 y ss.) acerca de la economización como ficción normativa.

${ }^{12}$ Así la estrecha y disyuntiva comprensión de Luhmann (1990: 289 y ss.) de la autonomía de los subsistemas. Los límites exteriores mencionados a continuación y gradaciones progresivas las reconoció bajo el término de "dependencia" -una duplicación conceptual poco razonable.
} 
integración social. La integración social refiere a la coordinación entre la sociedad y las personas, es decir, entre la sociedad y cada miembro individual de ella. Por su parte, desde el punto de vista de las organizaciones proveedoras de servicios subsistémicos de la economía, así como también de otros subsistemas, se puede partir de la observación de Luhmann (1981: 401) relativa a que estas organizaciones "proveen puestos de trabajo que ofrecen la oportunidad de ganar dinero". Para la sociedad moderna es ciertamente válido que el mantenimiento de la vida de la mayoría de sus miembros depende del trabajo asalariado (Conze 1972; Castel 1995): "El trabajo conduce a la oportunidad de adquirir propiedad - aunque sólo sea propiedad en alimentos para el consumo inmediato" (Luhmann 1988: 212). O bien una persona obtiene sus ingresos a través del propio empleo, o los obtiene indirectamente en el contexto de una relación íntima, bajo la forma de un presupuesto doméstico, como en el caso de los dependientes no económicamente activos de un trabajador ${ }^{13}$-un ama de casa o los hijos. No obstante, la gran mayoría de las personas que trabajan son a su vez trabajadores dependientes, es decir, empleados de una organización.

En tanto las organizaciones proveedoras de servicios subsistémicos son empresas, los individuos - como trabajadores asalariados individuales o colectivos- tienen que tomar en consideración los intereses de su empleador dentro de sus demandas de condiciones de trabajo para no poner en peligro sus propios empleos, y mientras peor esté la economía en su totalidad o en un sector en particular, menos opciones de "salida" tiene el trabajador para cambiar de una empresa a otra. Aquellos trabajadores que están ocupados en organizaciones proveedoras de servicios de otros subsistemas asumen esta situación de manera indirecta a través de la presión de economización. Las condiciones de trabajo y seguridad del empleo en los organismos administrativos estatales, universidades u hospitales están determinadas principalmente por los ingresos por la vía de impuestos estatales, y en la medida en que algunos de los puestos de estos empleados -no solamente de los funcionarios- del sector público son irrescindibles, se reducen con ello las oportunidades y la seguridad de empleo para grupos que soliciten empleo a posteriori.

La dependencia del dinero para la persona como trabajador actúa de manera similar a la dependencia del dinero por parte de las organizaciones proveedoras de servicios de los demás subsistemas sociales, esto constituye en cierto sentido la segunda línea propia de la presión de economización en la cual se manifiesta el primado social general de la economía. Este efecto de irradiación hacia todos los subsistemas sociales producido por la necesidad individual de obtener sustento durante toda la vida puede ser descrito de manera gruesa como sigue: es como si una persona en todo su querer y hacer tuviera que evitar todo lo que pudiera amenazar su puesto de trabajo - sus opciones de "salida" disponibles- o su empleabilidad entendida como su atractivo para los empleadores. Este imperativo se impone en parte como racionalidad consciente de la vida ${ }^{14}$ y en parte como selección, las personas que no obedecen a esta racionalidad son en última instancia excluidas del mercado de trabajo. El primado social total de la economía se hace evidente en aquellos casos extremos de extensa exclusión de una persona de su roles de público y de las ofertas de servicios de la mayoría de los subsistemas sociales. Aquí concuerda también Luhmann (1994, 1997: 618ss), quien generalmente describe carreras de "acumulación de exclusiones" asumiendo tácitamente que el desempleo es el punto de partida más común al menos para gran parte de estos descensos individuales ${ }^{15}$. En la medida en que la "precariedad" (Bourdieu, 1998) - la incertidumbre sobre el lugar de trabajo que provoca una incertidumbre correspondiente en los estándares de vida-

\footnotetext{
${ }^{13}$ Véase también Luhmann (1988: 323, n. al pie 30) “la dependencia de la familia del trabajo".

${ }^{14}$ La reconstrucción histórica del sujeto de la modernidad de Andreas Reckwitz (2006) ofrece abundancia de material de estudio al respecto -incluyendo el recientemente muy discutido concepto de "trabajo emprendedor" (Voss \& Pongratz 1998). Véase también la recopilación de material de Ulrich Bröcklings (2007) para el "ser emprendedor".

${ }^{15}$ Véase también la nota de Peter Fuchs (1997: 434) al respecto: "El peligro de la generalización de las exclusiones se establece (...) sobre la pérdida de trabajo".
} 
alcanza a las "capas sociales medias", no es posible sostener que se trata de un tema marginal en países como Alemania (Bude \& Willisch 2006; Burzan 2008; Vogel 2008).

Por todo lo anteriormente expuesto, la integración social de la sociedad está también prefigurada económicamente. Aquellos que tienen un empleo seguro y un ingreso adecuado constituyen un grupo de miembros de la sociedad para quienes los determinantes económicos de la vida se encuentran en gran medida neutralizados -a excepción de aquellos a quienes el propio funcionamiento del mercado de trabajo provee de imperativos de evitación y limitaciones de poder adquisitivo. Sin embargo, todos quienes no pertenecen a este grupo, lo que aplica social y mundialmente para la gran mayoría de la población, los que están fuera o corren el peligro de caer fuera de él, algo que actualmente inquieta parcialmente a los estratos medios y bajos de las regiones más privilegiadas del mundo, aprenden desde cerca el alcance del capitalismo. Éste bloquea a los "innecesarios" (Bude y Willisch 2006) -es decir a las personas que no son requeridas económicamente de manera permanente- el acceso normal a los servicios de la mayoría de los subsistemas. Los "innecesarios" pueden acceder a estos servicios sólo de manera reducida o son mantenidos bajo control en un nivel bajo en otros subsistemas: por el Estado del bienestar y el sistema de ayuda que trae acoplado (Baecker 1994), por el sistema legal y en última instancia por las fuerzas armadas.

\section{La inestabilidad intrasistémica de la economía}

Hasta aquí he explicado teóricamente los mecanismos y manifestaciones que evidencian el primado social total de la economía, por un lado respecto de los demás subsistemas, y por otro, respecto de los miembros individuales de la sociedad. En efecto, esta primacía podría ser totalmente inofensiva en términos sociales y por lo tanto teóricamente insignificante, si la economía fuese un subsistema social robusto el cual no pudiera ser afectado tan fácilmente por agentes externos o por dinámicas endógenas. Sin embargo este no es el caso. El papel de la economía capitalista, en conjunción con los demás subsistemas sociales y en relación con las personas, se representa más bien como el caso de un padre de familia de cuyo potencial y prosperidad dependen existencialmente todos los miembros de la familia, el cual sin embargo sufre de una enfermedad crónica y fuerza a éstos a hacer grandes concesiones y de manera apresurada ${ }^{16}$.

¿A qué se debe este estado enfermizo que requiere de tanta protección por parte de su entorno social? La respuesta a esta pregunta la da el segundo componente del modelo teórico acá discutido, el cual se concentra en el mercado como un mecanismo de gobernanza específico de la economía capitalista. La débil capacidad de ordenamiento de este mecanismo de gobernanza - según el argumento que a continuación desarrollaremos- se manifiesta para los oferentes de mercancías que acuden al mercado como una muy alta complejidad general para sus decisiones, lo que se traduce constantemente en efectos transintencionales, los que no sólo reproducen esta complejidad sino que también producen una inestabilidad inherente a todas las partes del ciclo económico. Esta inestabilidad se irradia luego como presión de economización hacia los demás subsistemas sociales y demanda allí permanentes consideraciones.

Un mercado capitalista -visto como un mecanismo de gobernanza- es una constelación de observaciones recíprocas motivada por un intercambio permanente, voluntario e interesado entre oferentes que compiten, a la manera de vendedores, y de demandantes de bienes escasos, que se presentan a la manera de compradores de mercancías (Heinemann 1976; Kraemer 1997: 20 y ss.; Baecker 2006: 85 y ss.; Czada 2007; Beckert 2007; Aspers \& Beckert 2008; Aspers 2009). Desde la perspectiva del vendedor individual

\footnotetext{
${ }^{16}$ Luhmann (1997: 769) constata esto de manera general: "en sociedades funcionalmente diferenciadas (...) domina el sistema con la cuota de fracasos más alta, debido a que el déficit de condiciones funcionales específicas no se puede compensar en ninguna otra parte, lo cual obliga por todos lados a severas adaptaciones".
} 
la situación se presenta de manera tal que, al igual que los otros vendedores, debe seducir a los compradores quienes a su vez desean pagar lo menos posible por los bienes ofrecidos: "Los mercados (...) se estructuran principalmente por vendedores en busca de compradores" (Fligstein 2001: 30) ${ }^{17}$. Cada vendedor debe decidir constantemente qué cantidad de bienes produce y a qué precio los pone a la venta, y toma estas decisiones a la luz de observaciones continuas de lo que en su entorno hacen cada uno de los demás vendedores y los correspondientes compradores -incluyendo otros potenciales compradores y vendedores. El orden social se produce en el mercado luego como acciones de intercambio coordinadas descentralizadamente y encadenadas de manera sucesiva entre particulares, donde los compañeros en estos intercambios -vendedores y compradores- son determinados cada uno solamente por sus oportunidades de intercambio y no interfieren en las oportunidades de intercambio de los otros.

El afán de ganancia es en la economía capitalista un impulso insaciable e incesantemente activo para el vendedor -dicho más exactamente: un afán de ganancia que satisfaga sus pretensiones. Ciertamente en la economía no siempre se alcanza el nivel 5 en la escala de economización antes introducida y muchas veces los vendedores se conforman derechamente por no caer bajo el nivel 3, es decir, en la evitación de las pérdidas.

Pero cuando la obtención de ganancias no parece posible por lo menos a mediano plazo, se pierde entonces la ambición empresarial específicamente capitalista. Si esto llegase a suceder en todos los ámbitos se derrumbaría la economía capitalista ${ }^{18}$. No obstante, sobre las posibilidades de realización de este afán de ganancia, los modelos neo- clásicos de los eventos económicos señalan que: "las ganancias sólo son posibles si los mercados se encuentran en desequilibrio" (Beckert 2007: 16). Dicho de otra manera: la búsqueda de intereses por parte de los vendedores termina en la introducción de desequilibrios en el mercado.

En primer lugar, tales desequilibrios pueden provenir factualmente de innovaciones por parte del vendedor -si es que hay nuevos productos y calidades de éstos, nuevas maneras de organización del proceso de producción, o nuevas formas de comercialización o financiación ${ }^{19}$. A través de innovaciones pueden los vendedores, así como sus competidores, escapar en última instancia del ruinoso callejón sin salida al que lleva la mera competencia de precios (Fligstein 2001: 68) ${ }^{20}$. En segundo lugar, los desequilibrios pueden producirse socialmente por vendedores nuevos que ingresan en un mercado y que desafían luego a los vendedores establecidos (Fligstein 2001: 32, 75 y ss.) -ya sea al principio mediante competencia de precios o mediante innovaciones. Ambos desequilibrios se deben a que los actores simplemente no siguen orientaciones, rutinas o

\footnotetext{
17 Hay excepciones para esta situación normal, como el caso de proveedores monopólicos que dependen de compradores o de una demanda de bienes temporalmente por encima del rango. Pero mientras no sean erigidas barreras políticas o de otro tipo a la entrada de los mercados, o existan "monopolios naturales", este tipo de situaciones ofrecen altos incentivos para la introducción de nuevos vendedores, que más temprano que tarde restauran la situación normal de competencia entre vendedores. Véase el concepto de "mercados contestables" (Baumol 1982).

${ }^{18}$ Esto no lo reconoce Luhmann (1988: 52 y ss.), pues para él la acción económica sólo se trata del restablecimiento de la capacidad de pago, es decir de la evitación de las pérdidas. Christoph Deutschmann (1999: 73) señala acertadamente: "La mera restauración de la solvencia no puede ser un motivo para gastar el dinero. La economía no proporcionaría otra perspectiva más que el reflujo de los pagos realizados, lo que evidentemente llevaría a la acumulación del dinero y por lo tanto a un alto en la producción y el intercambio". Se trataría más bien de "la regeneración rentable de la solvencia" (Deutschmann 2008: 3).

${ }^{19}$ Para Deutschmann (2007b), este potencial creativo inherente a la economía capitalista puede atribuirse en general al uso del trabajo humano basado en el mercado.

${ }^{20}$ Véase también el concepto de Chamberlin (1933) de la "competencia monopólica" el cual captura este modelo neoclásico de competencia que si bien está completamente oculto, se encuentra en todas partes del comportamiento real de los vendedores.
} 
normas institucionalizadas, sino que persiguen objetivos propios, para lo cual el mecanismo de mercado les da libertad de movimiento.

Si se entiende en general al desequilibrio como una constelación de actores, en la cual ninguna de las partes puede lograr mejores posiciones sin que cambien las acciones de los otros a través de un cambio en las propias acciones (Elster 1989: 101 y ss.), entonces el desequilibrio significa: los cambios en el comportamiento del otro en particular requieren de cambios en el comportamiento del propio actor y así sucesivamente, casi como en un perpetuum mobile. A partir de ambos desequilibrios en los mercados de la economía capitalista se produce la búsqueda de ganancia en condiciones competitivas, con lo cual se acrecientan profundas incertidumbres futuras para los vendedores. Éstos se ven obligados a adoptar una constante posición de alerta: ¿Qué hacen los otros vendedores?, ¿y cómo reaccionan los clientes al respecto? Dichas incertidumbres sobre el futuro son la forma temporal de la complejidad de la decisión con la que los vendedores de bienes en los mercados de la economía capitalista tienen que tratar, factual y socialmente.

Factualmente, los mercados se caracterizan por ser mecanismos de gobernanza para una formación de orden basada en gran medida en expectativas cognitivas. La coordinación de las acciones no sucede principalmente sobre la base de expectativas de lo que debiera ser, es decir sobre lo que la otra parte tiene permitido o debe hacer o abandonar, sino en base a estimaciones sobre aquello que los otros, ahora y en el futuro, quieren y pueden. ¿Qué aspiraciones de compra y venta tienen las contrapartes? ¿Qué alternativas tienen? ¿Qué poder de compra tienen o qué tan confiables son para cumplir lo que prometen? En un marcado contraste, otros mecanismos de gobernanza tales como jerarquías, comunidades o redes, actúan a través de expectativas normativas estables las cuales ofrecen al actor una mucho mayor reducción de complejidad para el procesamiento de información (Wiesenthal 2000; Schimank 2007).

Esta complejidad factual de los mercados aumenta socialmente a través de la de las decisiones de los otros basadas en observaciones y ajustes similares y también porque todos los vendedores, que son entre sí competidores, actúan de manera estratégica, es decir cada uno persigue el interés propio y con este fin protegen conocimientos secretos que engañan a los demás y buscan destapar otros conocimientos secretos para sí mismos. No existen restricciones reconocidas en los mercados para el interés propio y para si acaso azarosas coincidencias de intereses. Todos deben suponer más bien que sólo pueden conseguir algo para sí a costa de los demás. La desconfianza generalizada es allí una máxima de la sensatez y la cooperación o incluso la solidaridad no resultan convenientes.

Los vendedores poseen por tanto una disponibilidad para aprender. Cada uno de ellos debe dedicar una atención constante a sus contrapartes para explorar sus intenciones, posibilidades y limitaciones, y en lo posible anticipar los cambios o al menos poder reflexionar sobre ellos y poder adaptar flexiblemente en todo momento sus propias decisiones. Pero si alguien está dispuesto a aprender con respecto de todos, carece de aquella fiabilidad que ofrecen permanentemente las normas y autoridades establecidas por las jerarquías, las orientaciones y rutinas arraigadas de las comunidades o las posiciones de veto por todos conocidas en las redes. El orden social se produce en cambio en los mercados solamente como una permanente adaptación mutua con el fin de que se pueda continuar con la marcha.

Situaciones individuales de decisión con una alta complejidad factual, social y temporal suceden constantemente también en otros subsistemas sociales. Sin embargo sólo en la economía capitalista es dicho nivel de complejidad la regla, pues el mecanismo dominante para los vendedores de mercancías ya no reduce complejidad -dicho de otra manera, ya no crea orden. Llevando este pensamiento un poco más lejos: solamente en la economía, 
donde decisiones de tal complejidad ocurren a menudo, se puede suponer que los actores interactúen a menudo entre sí y funcionen en conjunto, por lo cual la complejidad se reproduce en vez de reducirse - como por el contrario sucede en otras partes donde se dan peaks singulares de complejidad en la sucesión de decisiones.

Debido a que el mecanismo de mercado muestra un "déficit endógeno de gobernanza" 21 tan evidente, la economía capitalista está modelada de manera diferente a la concepción neoclásica, es decir, la economía capitalista nunca ha sido una "economía de mercado" pura. Este mecanismo de gobernanza ha estado más bien siempre acompañado por otros mecanismos de gobernanza, y ciertamente bajo la forma de tres tipos de introducción de los mercados. En primer lugar, como introducción de los participantes del mercado en redes y en otro tipo de relaciones, incluso en monopolios -los que fijan precios y el reparto en los mercados- o en empresas como organizaciones jerárquicas formales. En segundo lugar, la introducción del mercado en una diversidad de arreglos institucionales, en parte como un conjunto jerárquico de normas jurídicas o estándares técnicos, y en parte como formas transmitidas a través de comunidades acerca del trato entre participantes del mercado, como por ejemplo los estándares de comportamiento del "comerciante honesto". Finalmente en tercer lugar, como introducción de los eventos económicos en patrones de orientación compartidos culturalmente, como por ejemplo en los conocimientos canonizados por parte de comunidades de trabajadores y profesionales y otras "comunidades epistémicas", mitos de racionalidad y modas, entre otros (Beckert 2007: 9 y ss.).

Todo esto sirve, mirado desde un punto de vista funcionalista, para incrementar la seguridad de expectativas mutuas, algo que necesitan todos los participantes del mercado -ya sea para que el vendedor pueda obtener ganancias o el comprador pueda pagar lo menos posible. En el "caos social" de un "intercambio azaroso" (Fligstein 2001: 21, 30) no sería posible ni siquiera un cálculo medianamente confiable sobre los costos, precios o ganancias. Como vendedor dentro de un mercado determinado se presentaría una amenaza constante mucho mayor para la propia existencia: "la participación de los vendedores en la arena es de supervivencia" (Fligstein 2001: 31). La seguridad de expectativas es una condición sine qua non para la persecución permanente de las ventajas propias del intercambio. Sin embargo -y contra la interpretación exagerada del "desanclaje" de la economía capitalista respecto de su entorno social- las introducciones del mercado en la sociedad que no se han perdido no logran estar cerca siquiera de superar el "déficit endógeno de gobernanza" de la economía capitalista: "A pesar de los elaborados mecanismos y reglas sociales que guían la interacción en el mercado, éstos son inherentemente inestables desde el punto de vista de los vendedores" (Fligstein 2001: 32). Heyman Minsky (1986: 9 y s.) lo constata lacónicamente: "El principal defecto de nuestro tipo de economía es que es inestable. Dicha inestabilidad no se debe a choques externos. (...) La inestabilidad se debe a los procesos internos de nuestro tipo de economía".

Uno podría preguntarse: ¿por qué la sociedad adopta de forma permanente la débil capacidad de ordenamiento de los mercados de la economía capitalista?, ¿no resulta factible mejor su sustitución, ya sea mediante otros mecanismos de gobernanza más sólidos o, de manera más radical, mediante su abolición y sustitución por otros mecanismos? Como es bien sabido, se han dado experimentos reales de este tipo y es muy probable que se sigan dando, desde todo el abanico de las intervenciones sociales y del Estado de bienestar, incluyendo la planificación económica socialista. Éstos han traído consigo ciertamente mucha más seguridad de expectativas a la economía pero en determinado punto a costa de una seria devaluación de los rendimientos de las organizaciones proveedoras de servicios de los demás subsistemas y de los miembros

\footnotetext{
${ }^{21}$ Adaptando un concepto de Gläser \& Lange (2007: 435).
} 
individuales de la sociedad, los cuales desde hace ya un largo tiempo son dependientes de los mercados de la economía capitalista para la persecución de sus objetivos: "La sociedad de mercado ha producido más ingresos, riqueza, bienes y servicios que cualquier otra forma de organización social humana" (Fligstein 2001: 3). Lo que aquí se señala generosamente como "sociedad" sería más correcto denominar "economía". Prácticamente nadie desea seriamente prescindir de estos logros del capitalismo. Incluso en medio de una profunda crisis económica como la actual y que le ha acarreado descrédito al capitalismo, dos tercios de los alemanes entrevistados por el semanario DIE ZEIT (edición del 14/5/2009) responden a la pregunta: "ise debe cambiar profundamente nuestro sistema económico debido a la crisis?" con un "no" -aunque lo que probablemente la mayoría intuye es que estos logros no deben ser dejados solamente a costa de los desequilibrios del mercado. Así como en general la sociabilidad no puede proporcionar simultáneamente una alta seguridad de expectativas junto con un gran margen de movimiento para la persecución de objetivos individuales, no se puede concebir ningún sistema económico el cual combine un orden muy estable con una alta eficiencia ${ }^{22}$.

Esto significa, no obstante, que tanto la "enorme acumulación de mercancías" (Marx 1859: 15) de la economía capitalista, así como la autonomía de los demás subsistemas sociales, son hechos a priori de la vida moderna. Es decir, "para la diferenciación funcional" -y con ella para el capitalismo- "no hay alternativa" (Luhmann 1986: 76). Uno tiene que vivir permanentemente con la inestabilidad económica y su influencia en toda la sociedad. Dado que el mecanismo de mercado del sistema económico se extiende por todos lados, las turbulencias que se producen localmente no pueden en su mayoría ser limitadas, sino que éstas azotan rápidamente, mediante mecanismos de "amplificación de desviaciones" (Maruyama 1963), más arriba en los mercados financieros, ya sea a la manera de una "racionalidad de manada" (Devenow \& Welch 1996; Kindleberger \& Aliber 2005; Windolf 2008), como espirales de deflación o inflación (Baumgartner \& Burns 1980; Minsky 1986), o también como dependencias del camino de la evolución tecnológica, de las modas en el management o de las tendencias del consumo (Deutschmann 2007b). La globalización, que avanza mayormente en el sistema económico como parte de la sociedad mundial funcionalmente diferenciada, potencia los efectos a largo plazo de estos desequilibrios en la economía mundial y al mismo tiempo hace todo aún más imprevisible para los actores. La mayoría de los inversionistas, empresas, consumidores y trabajadores a menudo ni siquiera sospechan que han sido afectados por turbulencias creada en otro lugar.

Dicho de manera resumida, y de acuerdo al modelo de ilustración sociológica de Esser (1993: 1 y ss.):

- La economía capitalista abandona al vendedor de mercancías al mecanismo de gobernanza del mercado, el cual como lógica de situación confronta al comportamiento de decisión del vendedor -su lógica de selección- con una muy alta complejidad.

- La acción de selección tiene lugar entonces esencialmente sobre la base de poco más de media docena de patrones simples de comportamiento, los cuales se orientan en términos factuales a menudo hacia niveles de exigencia, "puntos focales" y "marcos" que distorsionan la realidad, en términos temporales hacia rutas elegidas y supuestos lineales, así como socialmente hacia comparaciones o imitaciones de los demás, o una separación consciente de ellos ${ }^{23}$.

\footnotetext{
${ }^{22}$ Acerca de las "variedades de capitalismo" nacionales, véase como panorama general la obra de Jackson \& Deeg (2006). Esto se puede entender también como diferentes compensaciones entre inestabilidad y performance, como se ha preferido en las diversas "culturas de la modernidad" (Münch 1986).

${ }^{23}$ Estos modelos son demostrados por la "economía del comportamiento" en conexión con la psicología cognitiva y de la toma de decisiones (Rabin 1998; Goldberg \& Nitsch 1999; Paul 2004: 181ss.). Detrás se ubican mecanismos heurísticos
} 
- A partir de la articulación de la acción entre el vendedor que interactúa con los compradores, se produce un impulso en la actividad económica como lógica de agregación que crea permanentemente desequilibrios y por lo tanto inestabilidad en este subsistema social.

La sociedad capitalista combina -de este modo se pueden resumir los dos primeros componentes del modelo teórico propuesto- una débil formación interna de orden en la economía con una alta amenaza externa de orden: la economía capitalista es inherentemente inestable y propensa a las crisis y esto se filtra hacia los otros subsistemas sociales como amenazas a sus autonomías causadas por presiones de economización.

\section{El primado social total como profecía autocumplida}

El argumento presentado hasta ahora ha explicado el primado social general de la economía capitalista basándose en características estructurales de la sociedad funcionalmente diferenciada y su economía capitalista. Desde el punto de vista de la sociología del conocimiento las estructuras de la sociedad se consideran sobrepasadas por interpretaciones culturales, con lo cual la relación entre ambas permanece abierta. Algunos patrones culturales de orientación se corresponden exactamente con el esquema de Marx "base/ superestructura" y reflejan por tanto únicamente situaciones estructurales. En otros casos puede ocurrir inversamente lo contrario, la "superestructura" cultural pone bajo presión de adaptación a la "base". Puede ocurrir también que estructura y cultura se formen en gran medida de manera independientemente una respecto de la otra, o surgidas de manera independiente ambas resultan tener luego "afinidad electiva" y se estabilicen mutuamente. Entre estructuras y patrones culturales altamente complejos como los anteriormente descritos, una diferenciación funcional económicamente prefigurada por un lado y una cultura de la modernidad por el otro lado, son posibles de imaginar todos estos tipos de relaciones en coexistencia y de manera sucesiva. Sin poder profundizar acá sobre este tema, puede esbozarse la perspectiva teórica de una cultura capitalista de la modernidad como el tercer componente del modelo que he presentado.

Como ocurre generalmente que los actores suelen hacerse ideas sobre la naturaleza del mundo en el que se mueven, los miembros de la sociedad moderna llevan ciertas imágenes culturalmente ancladas en torno a éste. Se puede suponer que tales imágenes de la sociedad, por distorsionadas que pudieran llegar a ser, dominan la acción -ya sea en el día a día, así como en el caso de la formación política de la sociedad o en los planes de inversión de largo alcance por parte de empresas o universidades. Suponemos por lo general que lo incorrecto, aquel conocimiento que no se corresponde con la realidad, se corrige hasta su falsificación completa en el test de realidad de la acción. Esto sin embargo no es válido para aquella forma de conocimiento que Robert K. Merton (1948: 401, en cursivas en el original) caracterizó en el sentido del "teorema de Thomas" como "profecía autocumplida": "una definición inicial falsa de la situación que despierta un nuevo comportamiento que hace que dicha falsa concepción original de la situación se vuelva verdadera". Más exactamente: la acción articulada de una masa crítica de actores sobre la base de una misma definición de la situación conduce luego no sólo a la confirmación mutua entre estos actores sobre dicha definición, lo que constituiría solamente una ilusión colectiva compartida -como por ejemplo un delirio religioso-, sino que además se produce de acuerdo a esta definición una refiguración de la realidad, la cual asumen como propia finalmente más y más actores -o debieran hacerlo (Henshel 1978). El ejemplo que da Merton, y que posee plena vigencia actual, es la quiebra de un

psicológicamente anclados "que nos hacen inteligentes" (Gigerenzer \& Todd 1999) -sólo cuando no ingresan en un mercado basado en la "lógica de la agregación". 
banco antes económicamente sano debido a rumores de que podría ser golpeado económicamente, y la reacción en cadena que resulta del retiro de capital de sus clientes, con lo cual el banco finalmente se encuentra realmente acabado.

Lo que sostenemos es esto: podría convertirse en una profecía auto- cumplida la situación de que la mayoría de los miembros de la sociedad o quienes toman las decisiones políticas miren a la economía como el subsistema dominante de la sociedad en su conjunto. Si es que la mayoría de los actores individuales, colectivos y corporativos ponen siempre en el primer plano de sus acciones a los intereses de la economía de manera incuestionable y sin un mayor examen, debido a que la prosperidad económica es vista como la condición más importante para el bienestar individual y de toda la sociedad, el primado de la economía se vuelve más fuerte pues antes de todo cosifica la "falsa conciencia"24. Todos los actores se confirman entre sí continua y recíprocamente mediante sus respectivas actuaciones, que "todos" -en cualquier caso, todos aquellos "sensatos"25 suponen este primado, y así dicho primado se institucionaliza. En la bancarrota, como fenómeno social acotado, todos ven al final de manera inequívoca la realidad: el banco es insolvente. El primado social total de la economía, que en la sociedad adopta diversas manifestaciones concretas, sólo es visible permanentemente como coherencia social intersubjetiva de apreciaciones.

De este modo se instala el concepto de una sociedad capitalista en una teoría de la diferenciación funcional de la sociedad moderna como una idea cultural directriz, la que siguiendo a Max Weber (1978: 252) funciona como un "guardagujas"* de la acción y del actor y determina la dinámica social. Si se supone un primado constituido y reproducido de esta manera puede ser muy difícil de refutar una situación de base mediante una acción que establezca una definición diferente de la situación. Tal acción quedaría sin consecuencias, en el sentido que nadie se vería obligado de modo alguno a tomar dicha definición de situación -o yendo más lejos: la acción podría incluso conducir a una aceptación de la definición de la situación de que vivimos en una sociedad capitalista, orientando tanto a los actores disidentes como al actor original de esta acción. Solamente cuando un número suficiente de actores lo suficientemente influyentes creen en la sociedad capitalista y en tanto mantienen esta creencia se cumple esta condición. No sin motivos habla Merton (1975: 402, en cursivas en el original) del "círculo vicioso de la profecía autocumplida". Esto no significa que dicha definición de situación esté establecida para siempre, pues entonces la sociedad capitalista, incluso si se basara solamente en una profecía auto- cumplida, no sería de ningún modo un mero "tigre de papel" el cual pudiera ser derrocado de un golpe mediante una "ilustración" adecuada. Los patrones culturales cosificados pueden tomar la forma de una "jaula de hierro de la servidumbre" (Weber) como ocurre con las estructuras de diferenciación descritas anteriormente.

¿Cuál podría ser entonces el impulso inicial de esta dinámica de cosificación?, ¿qué es lo que pone en marcha la profecía autocumplida de la sociedad capitalista? Si no se asume que estos patrones culturales reflejan situaciones estructurales realmente existentes, se debe entonces indicar que al igual que cualquier otra concepción cognitiva también esta imagen de la sociedad puede surgir totalmente por azar y puede luego extenderse -a pesar la alta improbabilidad de que esto suceda. Junto con dicho comienzo evolutivo puede haber también una fase de inicio menos azarosa, si es que determinados grupos de apoyo en la sociedad hacen de estos patrones culturales un elemento de su propia identidad colectiva y, posteriormente, un interés reflexivo para sí. De este modo, se

\footnotetext{
${ }^{24}$ Sobre el concepto de cosificación que sirve de base a lo anterior véase Berger \& Luckmann (1971: 106 y ss.)

${ }^{25}$ A los cuales no pertenecieron por ejemplo los jóvenes socialistas de principios de los años 70's, cuando -iy bajo la presidencia de Gerhard Schröder!- quisieron desafiar la "resistencia" de la economía.

[ $\mathrm{N}$ del T.] Se refiere al oficio de mover las agujas para los cambio de vía en las intersecciones de las líneas de los ferrocarriles.
} 
entiende que empresarios y managers exageren su rol estructural como tomadores de decisiones económicas, lo cual es visto como por la economía capitalista como un ethos intrínseco al "motor inmóvil" de la sociedad en su conjunto y como medida de todas las cosas en la sociedad. Esta autocomprensión profesional puede convertirse luego en fuente de interés para justificar la centralidad social total de la economía y la importancia de los tomadores de decisiones y la autonomía de sus decisiones por sobre otras influencias sociales. Esta amalgama de ideas e intereses de los actores económicos está rodeada de legitimaciones provenientes de las ciencias económicas como teorías de reflexión de la economía capitalista ${ }^{26}$-las que con claridad toman forma actualmente en el pensamiento neoliberal contemporáneo. Ciertamente se requeriría explicar luego cómo esta imagen de sociedad se extiende a los demás actores sociales. Aquí se debe mirar más de cerca a los medios de comunicación masiva como mecanismos centrales de difusión, así como también a la "planificación ideológica" (Luhmann 1962) como una amplificación enfocada del impulso inicial que contempla la profecía autocumplida.

Si se debilita esta condición de inicio y se postula que la idea de que vivimos en una sociedad capitalista corresponde a un momento anterior a las condiciones estructurales reales ${ }^{27}$, se puede pensar entonces en un "rezago cultural" el cual posteriormente no desaparece sino que funge como mecanismo de transición para restablecer los cimientos estructurales perdidos de la sociedad capitalista sobre su propia profecía autocumplida. Esta creencia en el capitalismo que no muere instantáneamente con la estructura capitalista lleva temporalmente a esta forma social, hasta que ésta se estabiliza de nuevo estructuralmente, apoyada culturalmente. En término generales resulta a todas luces válido que la creencia de que vivimos en una sociedad capitalista es convincente cuanto más rápido se extiende y se solidifica y cuanto más se corresponde con la realidad de las estructuras internas e intersistémicas de la economía. Esta creencia ampliamente compartida puede por supuesto también traducirse, de manera inversa, en regulaciones institucionales que constituyan al primado de estructuras fácticamente consolidadas entre la economía y los demás subsistemas, así como dentro de la propia economía. Cuando por ejemplo los fondos estatales de apoyo a la investigación científica son orientados programáticamente para la generación de medidas que aporten a las capacidades de innovación y de crecimiento de la economía, pues sería allí donde se juega la suerte y la desgracia de toda la sociedad, la investigación científica es dominada entonces en sus objetivos y plazos por los imperativos económicos. Las relaciones de correspondencia entre formas estructurales y patrones de orientación pueden seguir también solidificándose.

A pesar de que de este modo las relaciones entre los elementos estructurales y culturales antes señalados de la sociedad capitalista parecen al menos ser inverosímiles, se debe señalar finalmente al respecto lo siguiente: en principio, y desde la sociología del conocimiento, es posible una justificación de la sociedad funcionalmente diferenciada como una sociedad capitalista de manera totalmente independiente de la justificación relativa a las estructuras bosquejada previamente. Incluso si todo lo que he mencionado anteriormente como elementos estructurales del primado social de la economía capitalista no resulta teórica o empíricamente coherente, el capitalismo podría darse como una mera profecía autocumplida.

\section{Conclusión}

La tesis general tocante a la teoría social que hemos sostenido en el contexto de las reflexiones acá presentadas señala, formulada con toda claridad, lo siguiente: sólo se

\footnotetext{
${ }^{26}$ Véase en general el concepto de Michel Callon (1998: cita 23) relativo a la "incrustación de la economía en la economía".

${ }^{27}$ Esto lo puede imaginar incluso el propio Luhmann (1973: 79).
} 
puede hablar de una sociedad capitalista, sin contradecirse a sí mismo, en el contexto de una perspectiva que ve la modernidad como sociedad funcionalmente diferenciada incluso se deben deducir mutuamente la diferenciación funcional y el capitalismo. Cuando se formaba una diferenciación funcional de la sociedad, junto con la diferenciación de los demás subsistemas, la economía se diferenciaba como economía capitalista. Como he mostrado, ésta domina desde entonces a los demás subsistemas e incluso a la vida de los miembros individuales de la sociedad. Por otro lado, este dominio puede no llegar tan lejos-como he mostrado en otra ocasión (Schimank 2010)- de modo que amenace la autonomía de los demás subsistemas y de este modo ponga en peligro de manera permanente la diferenciación funcional, y la economía capitalista misma tampoco se libra como elemento central de su propio inventario. Esta es la tensión irreductible que caracteriza profundamente a la modernidad: "primado de la economía" y "resistencia de la sociedad" (Beckert 2009).

Como he destacado al inicio de estas reflexiones, no he señalado en las consideraciones anteriores, ni una demostración empírica de que vivimos en una sociedad capitalista, ni he operacionalizado teóricamente en indicadores empíricamente verificables las características derivadas de una sociedad capitalista. Si es que resulta plausible el modelo teórico que hemos puesto en discusión, quedaría entonces solamente dar luego estos dos pasos para su prueba socio- teórica. RM

\section{Bibliografía}

Aspers, P. (2009). How are markets made? Köln: MPIfG Working Paper 09/2.

Aspers, P. \& Beckert, J. (2008). Märkte. En A. Maurer (Ed.), Handbuch zur Wirtschaftssoziologie (pp. 225- 246). Wiesbaden: VS Verlag für Sozialwissenschaften.

Baecker, D. (1994). Soziale Hilfe als Funktionssystem der Gesellschaft. Zeitschrift für Soziologie, 23(2), 93- 110.

Baecker, D. (2006). Wirtschaftssoziologie. Bielefeld: Transcript.

Baumgartner, T. \& Burns, T. R. (1980). Inflation: The Outcome of Institutionalized Social Struggle over Income Distribution. Acta Sociologica, 23(1-2), 177- 186.

Baumol, W. J. (1982). Contestable Markets: An Uprising in The Theory of Industry Structure. American Economic Review, 72(1), 1-15.

Beckert, J. (1997). Grenzen des Marktes. Die sozialen Grundlagen wirtschaftlicher Effizienz. Frankfurt a.M./ New York: Campus.

Beckert, J. (2007). Die soziale Ordnung von Märkten. Köln: MPIfG Discussion Paper 07/6.

Beckert, J. (2009). Wirtschaftssoziologie als Gesellschaftstheorie. Zeitschrift für Soziologie, 38(3), 182- 197.

Berger, J. (2008). Kapitalismusanalyse und Kapitalismuskritik. En A. Maurer (Ed.), Handbuch der Wirtschaftssoziologie (pp. 363-381). Wiesbaden: VS Verlag für Sozialwissenschaften.

Berger P. L. \& Luckmann, T. (1971). The Social Construction of Reality. A Treatise in the Sociology of Knowledge. Harmondsworth: Penguin.

Bourdieu, P. (1998). Gegenfeuer. Wortmeldungen im Dienste des Widerstands gegen die neoliberale Invasion. Konstanz: UVK.

Bröckling, U. (2007). Das unternehmerische Selbst. Frankfurt a.M.: Suhrkamp.

Bude, H. \& Willisch, A. (Eds.) (2006). Das Problem der Exklusion. Ausgegrenzte, Entbehrliche, Überflüssige. Hamburg: Hamburger Edition.

Burzan, N. (2008). Die Absteiger: Angst und Verunsicherung in der Mitte der Gesellschaft. Aus Politik und Zeitgeschichte, 33- 34, 6- 12.

Callon, M. (1998). Introduction: The Embeddedness of Economic Markets in Economics. En (Ed.), The Laws of the Markets (pp. 1-57). Oxford: Blackwell.

Castel, R. (1995). Die Metamorphosen der sozialen Frage. Eine Chronik der Lohnarbeit. Konstanz: UVK. 
Chamberlin, E. H. (1933). The Theory of Monopolistic Competition. A Re-Orientation of the Theory of Value. Cambridge MA: Harvard University Press.

Conze, W. (1972). Beruf. En O. Brunner et al. (Eds.), Geschichtliche Grundbegriffe. Historisches Lexikon zur politisch-sozialen Sprache in Deutschland (Vol. 1, pp. 490507). Stuttgart: Klett- Cotta.

Czada, R. (2007). Markt. En A. Benz, S. Lütz, U. Schimank \& G. Simonis (Eds.), Handbuch Governance (pp. 68-81). Wiesbaden: VS Verlag für Sozialwissenschaften.

Dahrendorf, R. (1958). Homo Sociologicus. Versuch zur Geschichte, Bedeutung und Kritik der Kategorie der sozialen Rolle. En, Pfade aus Utopia (pp. 128- 194). München: Piper.

Deutschmann, C. (1999). Die Verheißung des absoluten Reichtums. Zur religiösen Natur des Kapitalismus. Frankfurt a.M./ New York: Campus.

Deutschmann, C. (2000). Geld als absolutes Mittel: Zur Aktualität von Simmels Geldtheorie. En, Kapitalistische Dynamik (pp. 41-54). Wiesbaden: VS Verlag für Sozialwissenschaften.

Deutschmann, C. (2007a). Geld als universales Inklusionsmedium moderner Gesellschaften. Vortrags- Ms. Tübingen.

Deutschmann, C. (2007b). Dynamische Konzepte institutioneller Einbettung. Vortrags- Ms. Tübingen.

Deutschmann, C. (2008). Ökonomisierung als Entzauberung des Geldes. Vortrags- Ms. Tübingen.

Devenow, A. \& Welch, I. (1996). Rational Herding in Financial Economics. European Economic Review, 40(3-5), 603-615.

Elster, J. (1989). Nuts and Bolts for the Social Sciences. Cambridge: Cambridge University Press.

Engartner, T. (2007). Privatisierung und Liberalisierung - Strategien zur Selbstentmachtung des öffentlichen Sektors. En C. Butterwegge, B. Lösch, \& R. Ptak (Eds.), Kritik des Neoliberalismus (pp. 87-133). Wiesbaden: VS Verlag für Sozialwissenschaften.

Esser, H. (1993). Soziologie - Allgemeine Grundlagen. Frankfurt a.M./ New York: Campus.

Fligstein, N. (2001). The Architecture of Markets. An Economic Sociology of Twenty-FirstCentury Capitalism. Princeton: Princeton University Press.

Fuchs, P. (1997). Weder Herd noch Heimstatt - Weder Fall noch Nichtfall. Doppelte Differenzierung im Mittelalter und in der Moderne. Soziale Systeme, 3(2), 413- 437.

Gigerenzer, G. \& Todd, P. M. (and the ABC Research Group) (1999). Simple Heuristics that Make us Smart. Oxford: Oxford University Press.

Gläser, J. \& Lange, S. (2007). Wissenschaft. En A. Benz, S. Lütz, U. Schimank, \& G. Simonis (Eds.), Handbuch Governance (pp. 437-451). Wiesbaden: VS Verlag für Sozialwissenschaften.

Goldberg, J. \& von Nitsch, R. (1999). Behavioral Finance. Gewinnen mit Kompetenz. München: FinanzBuch Verlag.

Grauhan, R.- R. (1975). Grenzen des Fortschritts? Widersprüche der gesellschaftlichen Rationalisierung. München: Beck.

Grauhan, R.- R. \& Hickel, R. (Eds.). (1978). Krise des Steuerstaats? Opladen: Westdeutscher Verlag.

Grauhan, R.- R. \& Lindner, W. (1974). Politik der Verstädterung. Frankfurt a.M./ New York: Campus.

Habermas, J. (1980). Handlung und System - Bemerkungen zu Parsons' Medientheorie. En W. Schluchter (Ed.), Verhalten, Handeln und System. Talcott Parsons' Beitrag zur Entwicklung der Sozialwissenschaften (pp. 68- 105). Frankfurt a.M.: Suhrkamp.

Heinemann, K. (1976). Elemente einer Soziologie des Marktes. Kölner Zeitschrift für Soziologie und Sozialpsychologie, 28(1), 48-69.

Henshel, R. L. (1978). Self- altering predictions. En J. Fowles (Ed.), Handbook of Futures Research (pp. 99- 125). Westport, Conn.: Greenwood Press.

Hickel, R. (Ed.). (1976). Die Finanzkrise des Steuerstaates. Frankfurt a.M.: Suhrkamp.

Illouz, E. (2003). Der Konsum der Romantik. Frankfurt a.M.: Suhrkamp. 
Jackson, G. \& Deeg, R. (2006). How Many Varieties of Capitalism? Comparing the Comparative Institutional Analyses of Capitalist Diversity. Köln: MPIfG Discussion Paper 06/2.

Jessen, J. (2005). Fegefeuer des Marktes. DIE ZEIT, 30, 33-34.

Jessop, B. (2002). The Future of the Capitalist State. Cambridge: Polity Press.

Kindleberger, C. \& Aliber, R. (2005). Manias, Panics, and Crashes. A History of Financial Crises. Hoboken, N.J.: Wiley.

Kraemer, K. (1997). Der Markt der Gesellschaft. Zu einer soziologischen Theorie der Marktvergesellschaftung. Opladen: Westdeutscher Verlag.

Kraemer, K. (2001). Kapitalistische Gesellschaft. En G. Kneer, A. Nassehi, \& M. Schroer (Eds.), Klassische Gesellschaftsbegriffe der Soziologie (pp. 111-138). München: Fink.

Kuchler, B. (2005). Das Medium Geld und die Dominanz der Wirtschaft in der Gesellschaft. Ms. Mainz.

Luhmann, N. (1962). Wahrheit und Ideologie. En, Soziologische Aufklärung (Vol. 1, pp. 5465). Opladen: Westdeutscher Verlag.

Luhmann, N. (1973). Selbst- Thematisierungen des Gesellschaftssystems. En, Soziologische Aufklärung (Vol. 2, pp. 72- 102). Opladen: Westdeutscher Verlag.

Luhmann, N. (1976). Generalized Media and the Problem of Contingency. In J. J. Loubser (Ed.), Explorations in General Theory in Social Science. Essays in Honor of Talcott Parsons (pp. 507- 532). New York: Free Press.

Luhmann, N. (1979). Identitätsgebrauch in selbstsubstitutiven Ordnungen, besonders Gesellschaften. En, Soziologische Aufklärung (Vol. 3, pp. 198-227). Opladen: Westdeutscher Verlag.

Luhmann, N. (1981). Organisationen im Wirtschaftssystem. En, Soziologische Aufklärung (Vol. 3, pp. 390-414). Opladen: Westdeutscher Verlag.

Luhmann, N. (1983). Anspruchsinflation im Krankheitssystem. Eine Stellungnahme aus gesellschaftstheoretischer Sicht. En P. Herder-Dorneich \& A. Schuller (Eds.), Die Anspruchsspirale. Schicksal oder Systemdefekt? (pp. 28-49). Stuttgart: Kohlhammer.

Luhmann, N. (1986). Alternative ohne Alternative. Die Paradoxie der „neuen sozialen Bewegungen“. En, Protest (pp. 75- 78). Frankfurt a.M.: Suhrkamp.

Luhmann, N. (1988). Die Wirtschaft der Gesellschaft. Frankfurt a.M.: Suhrkamp.

Luhmann, N. (1990). Die Wissenschaft der Gesellschaft. Frankfurt a.M.: Suhrkamp.

Luhmann, N. (1994). Inklusion und Exklusion. En, Soziologische Aufklärung. (Vol. 6, S. 234- 267). Opladen: Westdeutscher Verlag.

Luhmann, N. (1997). Die Gesellschaft der Gesellschaft. 2 Volúmenes. Frankfurt a.M.: Suhrkamp.

Lutz, B. (1984). Der kurze Traum immerwährender Prosperität. Eine Neuinterpretation der industriell-kapitalistischen Entwicklung im Europa des 20. Jahrhunderts. Frankfurt a.M./ New York: Campus.

Maruyama, M. (1963). The Second Cybernetics: Deviation-Amplifying in Mutual Causal Processes. General Systems Yearbook, 8, 233- 241.

Marx, K. (1859). Zur Kritik der politischen Ökonomie. En K. Marx \& F. Engels, Werke (Vol. 13, pp. 3- 160). Berlin: Dietz.

Merton, R. K. (1975). Die Self- Fulfilling prophecy. En, Soziologische Theorie und soziale Struktur (pp. 399-413). Berlin: de Gruyter.

Minsky, H. P. (1986). Stabilizing an Unstable Economy. New Haven: Yale University Press.

Münch, R. (1986). Die Kultur der Moderne. 2 Volúmenes. Frankfurt a.M.: Suhrkamp.

Offe, C. (1975). Berufsbildungsreform. Eine Fallstudie über Reformpolitik. Frankfurt a.M.: Suhrkamp.

Offe, C. (1984). Arbeitsgesellschaft. Frankfurt a.M./ New York: Campus.

Offe, C. \& Ronge, V. (1976). Thesen zur Begründung des Konzepts des „kapitalistischen Staates" und zur materialistischen Politikforschung. En C. Pozzoli (Ed.), Rahmenbedingungen und Schranken staatlichen Handelns ( $\mathrm{pp}$. 54-70). Frankfurt a.M.: Suhrkamp. 
Pahl, H. (2008). Das Geld in der modernen Gesellschaft. Marx und Luhmann im Vergleich. Frankfurt a.M./ New York: Campus.

Parsons, T. (1967a). On The Concept of Influence. En, Sociological Theory and Modern Society (pp. 355-382). New York: Free Press.

Parsons, T. (1967b). On The concept of Political Power. En, Sociological Theory and Modern Society (pp. 297- 354). New York: Free Press.

Parsons, T. (1968). On The Concept of Value- Commitments. Sociological Inquiry, 38(2), 135- 160.

Parsons, T. (1975a). Some Reflections on the Place of Force in Social Process. En, Sociological Theory and Modern Society (pp. 264- 296). New York: Free Press.

Parsons, T. (1975b). Gesellschaften. Frankfurt a.M.: Suhrkamp.

Parsons, T. (1976). Grundzüge des Sozialsystems. En, Zur Theorie sozialer Systeme (pp. 161-274). Opladen: Westdeutscher Verlag.

Parsons, T. \& Smelser, N. J. (1956). Economy and Society: A Study in the Integration of Economic and Social Theory. London: Routledge.

Paul, A. T. (2004). Die Gesellschaft des Geldes. Entwurf einer monetären Theorie der Moderne. Wiesbaden: VS Verlag für Sozialwissenschaften.

Rabin, M. (1998). Psychology and Economics. Journal of Economic Literature, 36(1), 11 46.

Reckwitz, A. (2006). Das hybride Subjekt. Eine Theorie der Subjektkulturen von der bürgerlichen Moderne zur Postmoderne. Weilerswist: Velbrück.

Schimank, U. (1996). Theorien gesellschaftlicher Differenzierung. Opladen: Leske + Budrich.

Schimank, U. (2002). Gesellschaftliche Teilsysteme und Strukturdynamiken. En U. Volkmann \& U. Schimank (Eds.), Soziologische Gegenwartsdiagnosen II Vergleichende Sekundäranalysen (pp. 15-49). Opladen: Leske + Budrich.

Schimank, U. (2005a). Funktionale Differenzierung und gesellschaftsweiter Primat von Teilsystemen - offene Fragen bei Parsons und Luhmann. Soziale Systeme, 11 (2), 395414.

Schimank, U. (2005b). Die Entscheidungsgesellschaft. Komplexität und Rationalität der Moderne. Wiesbaden: VS Verlag für Sozialwissenschaften.

Schimank, U. (2007). Elementare Mechanismen. En A. Benz, S. Lütz, U. Schimank \& G. Simonis (Eds.), Handbuch Governance (pp. 29-45). Wiesbaden: VS Verlag für Sozialwissenschaften.

Schimank, U . (2008). Gesellschaftliche Ökonomisierung und unternehmerisches Agieren. En A. Maurer \& U. Schimank (Eds.), Die Gesellschaft der Unternehmen - Die Unternehmen der Gesellschaft (pp. 220-236). Wiesbaden: VS für Sozialwissenschaften.

Schimank, U. (2009). Die funktional differenzierte kapitalistische Gesellschaft als Organisationsgesellschaft - eine theoretische Skizze. En M. Endreß \& T. Matys (Eds.), Die Ökonomie der Organisation - Die Organisation der Ökonomie (pp. 33-61). Wiesbaden: VS Verlag für Sozialwissenschaften

Schimank, U. (2010). „Vater Staat“: ein vorhersehbares Comeback. Staatsverständnis und Staatstätigkeit in der Moderne. der moderne staat, 3 (en prensa).

Schimank, U., \& Volkmann, U. (2008). Ökonomisierung der Gesellschaft. En A. Maurer (Ed.), Handbuch zur Wirtschaftssoziologie (pp. 382-393). Wiesbaden: VS Verlag für Sozialwissenschaften.

Sennett, R. (1998). Der flexible Mensch. Die Kultur des neuen Kapitalismus. Berlin: BerlinVerlag.

Simmel, G. (1989). Philosophie des Geldes. Frankfurt a.M.: Suhrkamp.

Vogel, B. (2008). Prekarität und Prekariat - Signalwörter neuer Ungleichheiten. Aus Politik und Zeitgeschichte, 33- 34, 12- 18.

Voß, G.- G. \& Pongratz, H. J. (1998). Der Arbeitskraftunternehmer. Eine neue Grundform der „Ware Arbeitskraft"? Kölner Zeitschrift für Soziologie und Sozialpsychologie, 50(1), 131-158. 
Weber, M. (1978). Gesammelte Aufsätze zur Religionssoziologie (Vol. 1). Tübingen: Mohr. Wiesenthal, H . (2000). Markt, Organisation und Gemeinschaft als „zweitbeste“ Verfahren sozialer Koordination. En R. Werle \& U. Schimank (Eds.), Gesellschaftliche Komplexität und kollektive Handlungsfähigkeit (pp. 44- 73). Frankfurt a.M./ New York: Campus.

Willke, G. (2006). Kapitalismus. Frankfurt a.M./ New York: Campus.

Windolf, P. (2005). Was ist Finanzmarkt- Kapitalismus? En (Ed.), Finanzmarkt-Kapitalismus. Analysen zum Wandel von Produktionsregimen. Sonderheft Nr. 45 der Kölner Zeitschrift für Soziologie und Sozialpsychologie (pp. 20-57). Wiesbaden: VS Verlag für Sozialwissenschaften.

Windolf, P. (2008). Eigentümer ohne Risiko. Die Dienstklasse des Finanzmarkt-

Kapitalismus. Zeitschrift für Soziologie, 37(6), 516-535.

\section{Sobre el autor}

Uwe Schimank es profesor del Instituto de Sociología de la Universidad de Bremen en Alemania. Doctor en Sociología por la Universidad de Bielefeld, Alemania. Entre sus áreas de especialización se encuentran: teoría sociológica, diagnósticos sociológicos del presente, sociología organizacional, sociología de la ciencia y sociología del deporte. Entre sus publicaciones se destacan: Differenzierung und Integration der modernen Gesellschaft: Beiträge zur akteurzentrierten Differenzierungstheorie (VS Verlag für Sozialwissenschaften, 2005), Teilsystemische Autonomie und politische Gesellschaftssteuerung. Beitrage zur akteurzentrierten Differenzierunsstheorie (VS Verlag für Sozialwissenschaften, 2006), Die Gesellschaft der Unternehmen - Die Unternehmen der Gesellschaft. Gesellschaftstheoretische Zugänge zum Wirtschaftsgeschehen (Editor, Junto a Andrea Maurer) (VS Verlag für Sozialwissenschaften, 2008).

uwe.schimank@uni-bremen.de

\section{Contacto}

Institut für Soziologie

Universität Bremen

Bibliothekstr. 1

Postfach 330440

D- 28359 Bremen

Deutschland

Recibido: Diciembre 2012

Aceptado: Marzo 2013 